Rhode Island College

Digital Commons @ RIC

$1-1-2011$

\title{
What Impact Does a Coordinated School Health Program Have on Health Behaviors in Rhode Island High School Students?
}

Dawn Britto

Rhode Island College

Follow this and additional works at: https://digitalcommons.ric.edu/etd

Part of the Public Health and Community Nursing Commons

\section{Recommended Citation}

Britto, Dawn, "What Impact Does a Coordinated School Health Program Have on Health Behaviors in Rhode Island High School Students?" (2011). Master's Theses, Dissertations, Graduate Research and Major Papers Overview. 203.

https://digitalcommons.ric.edu/etd/203

This Major Paper is brought to you for free and open access by the Master's Theses, Dissertations, Graduate Research and Major Papers at Digital Commons @ RIC. It has been accepted for inclusion in Master's Theses, Dissertations, Graduate Research and Major Papers Overview by an authorized administrator of Digital Commons @ RIC. For more information, please contact digitalcommons@ric.edu. 
WHAT IMPACT DOES A COORDINATED SCHOOL HEALTH PROGRAM

HAVE ON HEALTH BEHAVIORS IN RHODE ISLAND HIGH SCHOOL

STUDENTS?

A Major Paper Presented

By

Dawn Britto

Approved:

Committee Chairperson

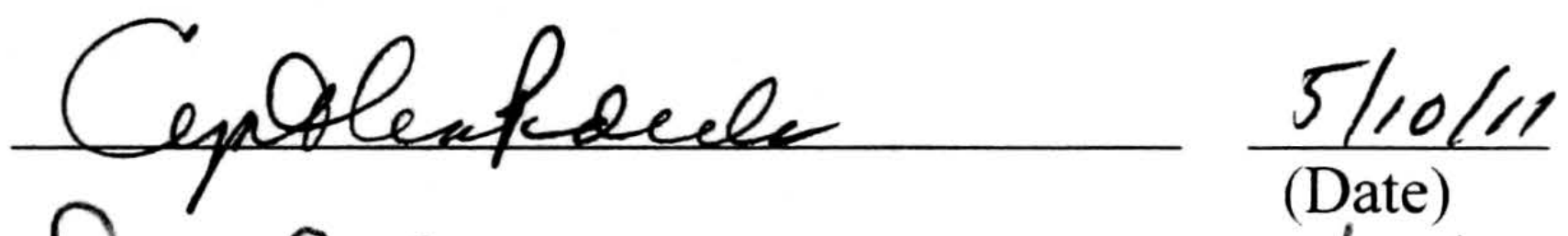

Committee Members

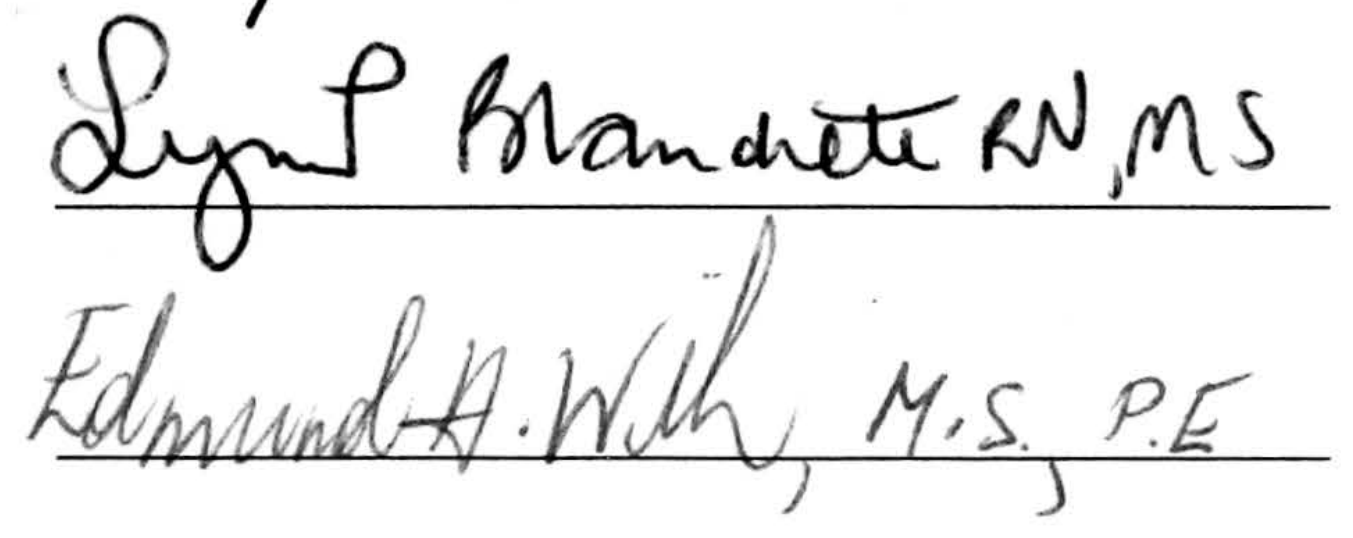

$\frac{51 / 8 / 2011}{\text { (Date) }}$

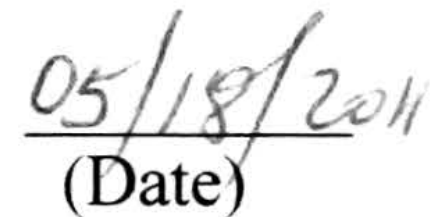

Director of Master's Program

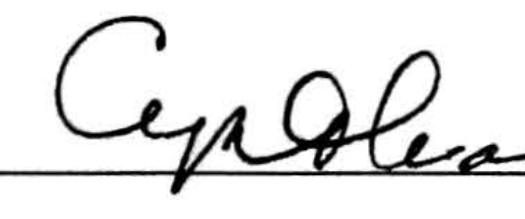

Rech

$\frac{5 / 10 / \mu}{\text { (Date) }}$

Dean, School of Nursing

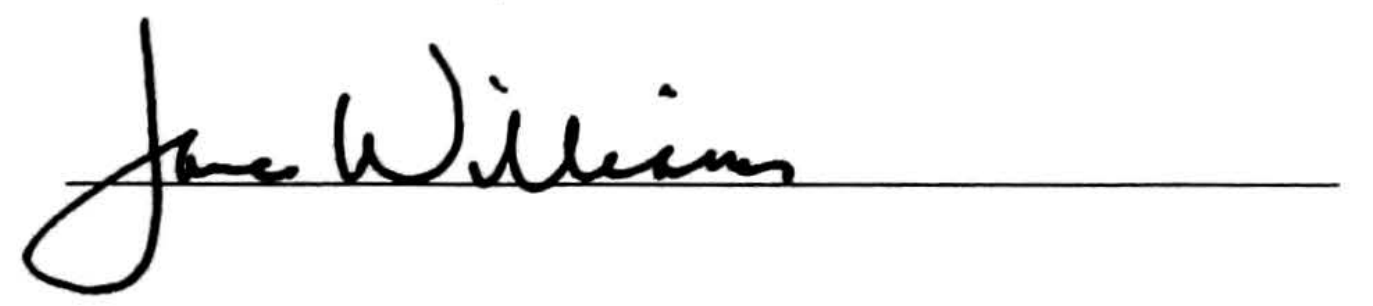

$\frac{7 / 28 / 2011}{\text { (Date) }}$ 


\section{WHAT IMPACT DOES A COORDINATED SCHOOL HEALTH PROGRAM HAVE ON HEALTH BEHAVIORS IN RHODE ISLAND HIGH SCHOOL STUDENTS?}

\section{RHODE ISLAND COLLEGE}

by

Dawn Britto

A Major Paper Submitted in Partial Fulfillment of the Requirements

for the Degree of Master of Science in Nursing

in

The School of Nursing

Rhode Island College 


\begin{abstract}
Society has become increasingly concerned with minimizing health-risk behaviors in young people grades K-12. These risky behaviors contribute to the leading causes of morbidity and mortality, which are often established during childhood and adolescence, extend into adưthood, and are interrelated and preventable. School health programs can play a unique and important role in the lives of youth by helping improve their healthrelated knowledge, attitudes and skills through comprehensive coordinated school health education. A high-quality school health program is a coordinated and comprehensive set of courses, services, practices, and policies that meet the health and safety needs of students and school staff in kindergarten through grade 12.
\end{abstract}

The purpose of this project was to evaluate the impact of Coordinated School Health Program on health behaviors of Rhode Island high school students. This was accomplished by analyzing retrospective health surveillance data (in the areas of tobacco, alcohol use, unhealthy eating, and inadequate physical activity) from the 2009 Youth Risk Behavior Survey (YRBS) and 2008 InformationWorks!, and comparing it to Healthy People 2010 target measure percentiles. The percentage comparisons from each data source and topic area suggested if students at grade levels 9-12 had demonstrated movement along the continuum to the prospective achievement of HP 2010 target measures.

Results from the RI 2009 YRBS and InformationWorks! survey indicated that many high school students did not demonstrate substantial movement toward target achievement (continue to engage in behaviors that place them at risk for the leading 
causes of morbidity and mortality). In analyzing the 2009 Youth Risk Behavior Survey and 2008 InformationWorks!, tobacco use met HP 2010 target measures for all ages, and alcohol use met measure for youth under 13 years of age. Clearly, the range of unmet HP 2010 target measures (in alcohol use, unhealthy eating, and inadequate physical activity) may explain why coordinated health programs as envisioned by the model have not become a sustainable reality in many local communities. Research indicates that more effective school health programs and other policy and programmatic interventions are needed to reduce risk and improve health outcomes among youth.

Advanced Practice Nurses (APN) could: lead community driven efforts for multifaceted data compilation that are generated from diverse sources of data, and useful in determining community health needs, and securing funding for resources (school materials, grass root programs, health clinics, etc...); help implement evidenced based health promotion activities that are geared toward achieving successful outcomes; provide continuing education units for professional development that is specific to health education, and primary prevention (recruit licensed/certified professionals to develop curriculum and teach health education to students); develop health education policies that identify national standardized health curriculum that is age appropriate, culturally relevant, and based on current health risk trends; and APN's should be recognized as experts in health education, scholars in evidenced based best practice, and utilize their expertise in all phases of curriculum development, teaching, and program evaluation. 


\section{Table of Contents}

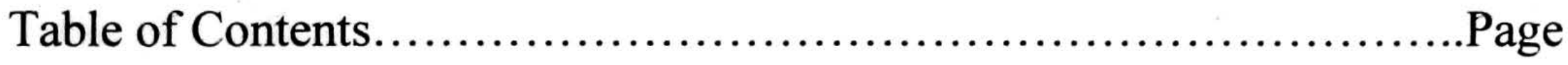

Statement of Problem.......................................................

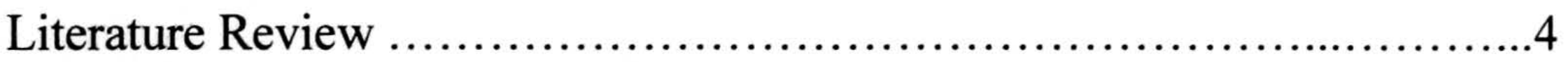

Theoretical Framework ................................................. 21

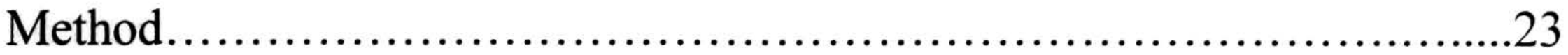

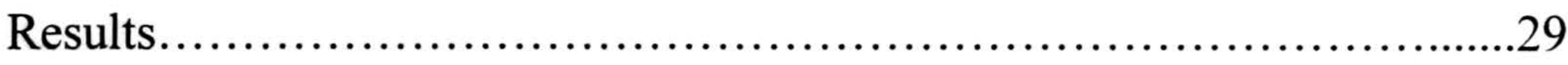

Summary and Conclusions................................................

Recommendations and Implications for Advanced Nursing Practice...........41

References.............................................................

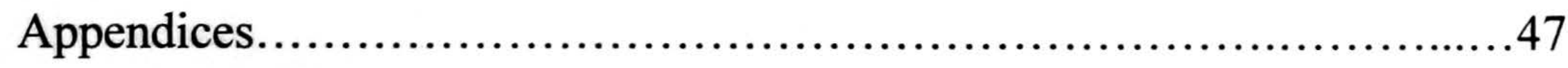


What Impact Does a Coordinated School Health Program Have on Health Behaviors in Rhode Island High School Students?

\author{
Rhode Island College
}

Dawn Britto 
What Impact Does a Coordinated School Health Program Have on Health Behaviors in RI High School Students?

\section{Statement of Problem}

Our nations young people are at risk and the seriousness of the health risks endanger young people and their ability to achieve future goals. "For the first time in the history of this country young people are less healthy and less prepared to take their places in society than were their parents (Heeb, 2005, p1195). Concern about the health and educational achievement of young people and the recognition that education and health are inextricably intertwined have resulted in considerable interest in and attention to the quality of health programs in our schools and communities.

The overall goal of any school system is to develop infrastructure at the state and local levels that will coordinate health programs to improve the health and academic success of children. In order to achieve this goal, schools are developing coordinated school health programs, a model which includes health education, health services, healthy school environment, counseling, psychological and social services, physical education, nutrition services, staff wellness, and family and community involvement (Marx, Wooley, \& Northrop, 1998). Many of these programs and services exist in schools and communities, yet the system of delivery is often fragmented and uncoordinated. A coordinated approach to school health improves the health of young people and enhances their capacity to learn through the support of families, schools, and communities working together (Murray, N. G., Low, B. J., Hollis, C., Cross, A. W. and Davis, S., 2007). 
At its core, coordinated school health is about keeping students healthy over time, reinforcing positive health behaviors throughout the school day, and making it clear that good health and learning go hand in hand (Murray et al.). Recent research findings from across the United States (US) strongly indicate that collaborative efforts among family, community and the schools are the most effective approaches for both prevention and intervention (Murray et al.). Based on what we know about the current trends, this project will answer the question,"What impact does a Coordinated School Health Program have on health behaviors in RI high school students?" 


\section{Literature Review}

\section{Youth Health Objectives}

In the US, 53 million young people attend nearly 129,000 schools for about six hours of classroom time each day for up to 13 of the most formative years of their lives; more than $95 \%$ of young people aged 5-17 years are enrolled in school (Center for Disease Control and Prevention [CDC], 2009). Because schools are the only institutions that can reach nearly all youth, they are in a unique position to improve both the education and health status of young people throughout the nation.

Modern school health programs can be developed to improve specific knowledge and attitudes about health behaviors. The programs goals are designed to enable students to acquire information, attitudes, and skills about health. Programs must also improve specific health behavioral and educational outcomes (National Association of State Boards of Education [NASBE], 2002).

The goal of acquiring information, attitudes and skills about health, or any other topic, must determine what standard knowledge about that topic is most important for students at various grade levels to acquire; it also must assess the extent to which students have acquired it. This is especially critical today, since the development of standardsbased education is a principal means to reform education and improve student health (Allensworth \& Kolbe, 1987).

Another program goal is to improve specific health behaviors and outcomes (NASBE, 2002). Undeniably, modern school health programs could be one of the most efficient means nations might employ to prevent their most serious health problems. For 
example, in the US, some of the most serious health problems from which young people suffer result from just three types of behavior: behaviors that result in unintentional and intentional injuries; alcohol and other drug use; and sexual risk behaviors (CDC, 2009). For some young people, unhealthy behaviors become habits; so changing them can be very difficult. They are more likely to make changes in their habits if they set a specific goal for themselves, focus on one high-risk behavior at a time, increase their knowledge base, and decrease the likely hood of exposure (Marx et al., 1998).

Among our nation's $9-12^{\text {th }}$ grade students, $31 \%$ have been a passenger with a driver who had been drinking alcohol, $33 \%$ have been in a physical fight, $9 \%$ have attempted suicide, and $46 \%$ have engaged in sexual intercourse. These behaviors often are interrelated and cause not only health problems and physical suffering, but serious educational and social problems as well (Rhode Island Department of Education [RIDOE], 2008). In the US, adults 25 years of age and older account for $72 \%$ of all deaths. An enormous number of injuries that do not result in death are caused by five chronic diseases: heart disease and stroke (41\%); cancer $(23 \%)$; chronic obstructive pulmonary disease $(5 \%)$; and diabetes. These deaths and illnesses largely result from three types of behavior: tobacco use; unhealthy dietary patterns; and inadequate physical activity (CDC, 2009). Among our nation's $9-12^{\text {th }}$ graders, $29 \%$ smoke cigarettes, $79 \%$ do not eat the recommended amount of fruits and vegetables, $68 \%$ do not attend daily physical education classes, and $11 \%$ are overweight (RIDOE, 2008). These percentages do not reflect an increase in positive behaviors or outcomes; instead, they reflect an 
ongoing need to improve health knowledge, attitudes, and educational outcomes for young people.

The last goal is geared toward improving the overall health outcomes of young people. Decreasing risky behaviors in young people who are unhealthy, who are ill or injured, hungry or depressed, abusing drugs or are pregnant could benefit from health education and intervention. Those who drop out of school experience more health problems, delayed employment, and poverty. Conversely, people who acquire more education tend to not only be healthier and practice fewer health risk behaviors, but their children tend to be healthier and practice fewer heath risk behaviors (RIDOE, 2008).

Supporting school health programs to improve the health status of our nation's young people has never been more important. Many of the health challenges facing young people today are different from those of past decades. Advances in medications and vaccines have largely reduced the illness, disability, and death that common infectious diseases once caused among children (CDC, 2009). Today, the health of young people, and the adults they will become, is critically linked to the health-related behaviors they choose to adopt. Table 1 highlights percentages of $9-12^{\text {th }}$ graders with high risk practices in tobacco and drug use. 
Table 1

2007-2008 9-12 ${ }^{\text {th }}$ Grade Student Reports of Health Risk Practices by Grade Level

\begin{tabular}{|c|c|c|c|c|c|c|c|c|c|c|c|c|c|c|c|}
\hline & & & \multicolumn{13}{|c|}{ Grade level } \\
\hline \multicolumn{3}{|c|}{ Overall } & \multicolumn{3}{|c|}{$9^{\text {th }}$} & \multicolumn{4}{|c|}{ 10th } & \multicolumn{3}{|c|}{ 11th } & \multicolumn{3}{|c|}{$12^{\text {th }}$} \\
\hline 77-98 & b6-07 & 77-08 & 77-98 & p6-07 & p7-08 & & 7-98 & $\begin{array}{l}06- \\
07\end{array}$ & $\begin{array}{l}07- \\
08\end{array}$ & 77-98 & $\begin{array}{l}06- \\
07\end{array}$ & 77-08 & 77-98 & p6-07 & $\begin{array}{l}07- \\
08\end{array}$ \\
\hline
\end{tabular}

During the past 30 days, on how many days (if any) did you smoke cigarettes? *

\begin{tabular}{|c|c|c|c|c|c|c|c|c|c|c|c|}
\hline None & •. & 83 & 81 & 84 & 84 & 85 & 80 & 86 & 83 & 78 & 77 \\
\hline 1-5 days & $\ddot{*}$ & 7 & 7 & 7 & 6 & 6 & 7 & 6 & 6 & 9 & 8 \\
\hline 6-9 days & $\ddot{*}$ & 3 & 5 & 3 & 4 & 4 & 5 & 2 & 5 & 4 & 5 \\
\hline 10-19 days & $\ddot{*}$ & 2 & 3 & 2 & 2 & 2 & 2 & 2 & 3 & 3 & 4 \\
\hline 20-30 days & $\ddot{*}$ & 4 & 5 & 4 & 4 & 4 & 5 & 4 & 3 & 5 & 7 \\
\hline
\end{tabular}

During the past 30 days, how many times (if any) did you use chewing tobacco or snuff?

\begin{tabular}{|l|l|l|l|l|l|l|l|l|l|l|l|l|l|l|l|}
\hline None & 89 & 88 & 84 & 88 & 88 & 86 & 89 & 88 & 84 & 91 & 90 & 87 & 90 & 84 & 80 \\
\hline $1-5$ times & 4 & 5 & 5 & 4 & 4 & 5 & 4 & 5 & 6 & 4 & 5 & 5 & 3 & 6 & 6 \\
\hline $6-9$ times & 4 & 3 & 4 & 5 & 3 & 4 & 4 & 3 & 4 & 3 & 3 & 4 & 3 & 4 & 6 \\
\hline $10-19$ times & 1 & 2 & 2 & 2 & 2 & 2 & 1 & 1 & 2 & 1 & 1 & 2 & 1 & 2 & 3 \\
\hline 20 or more times & 1 & 3 & 4 & 2 & 3 & 3 & 1 & 3 & 4 & 1 & 1 & 3 & 2 & 4 & 5 \\
\hline
\end{tabular}

During the past $\mathbf{3 0}$ days, how many times (if any) did you use illegal drugs (such as marijuana, uppers, downers, etc.)?

\begin{tabular}{|l|l|l|l|l|l|l|l|l|l|l|l|l|l|l|l|}
\hline None & 75 & 79 & 77 & 74 & 81 & 80 & 75 & 79 & 76 & 77 & 82 & 78 & 76 & 74 & 72 \\
\hline $1-2$ times & 11 & 7 & 8 & 11 & 6 & 7 & 10 & 8 & 8 & 10 & 7 & 8 & 10 & 9 & 9 \\
\hline $3-5$ times & 6 & 5 & 6 & 7 & 4 & 5 & 7 & 5 & 6 & 5 & 5 & 5 & 6 & 6 & 6 \\
\hline $6-10$ times & 2 & 2 & 3 & 2 & 3 & 2 & 3 & 3 & 3 & 2 & 2 & 3 & 2 & 3 & 4 \\
\hline More than 10 times & 6 & 6 & 7 & 5 & 5 & 5 & 6 & 5 & 7 & 6 & 5 & 6 & 5 & 8 & 9 \\
\hline
\end{tabular}

During the past $\mathbf{3 0}$ days, how many different times (if any) have you had at least one drink of alcohol (such as wine, wine coolers, beer, mixed drinks, or hard liquor)? Please report the number of times or days, not the number of drinks.

\begin{tabular}{|l|l|l|l|l|l|l|l|l|l|l|l|l|l|l|l|}
\hline 0 times & 56 & 64 & 67 & 56 & 67 & 70 & 57 & 62 & 65 & 57 & 69 & 67 & 52 & 59 & 63 \\
\hline $1-5$ times & 27 & 22 & 19 & 26 & 21 & 18 & 27 & 24 & 19 & 26 & 20 & 20 & 31 & 23 & 18 \\
\hline $6-9$ times & 10 & 6 & 6 & 10 & 5 & 4 & 8 & 7 & 7 & 10 & 5 & 6 & 9 & 8 & 7 \\
\hline $10-19$ times & 4 & 3 & 4 & 4 & 3 & 3 & 4 & 3 & 3 & 4 & 2 & 3 & 4 & 3 & 5 \\
\hline
\end{tabular}


Source: Information Works! 2008 SALT Survey

Certain behaviors that are often established during youth contribute markedly to today's major causes of death, such as heart disease, cancer, and injuries. These behaviors include using tobacco, eating unhealthy foods, not being physically active, using alcohol and other drugs, engaging in sexual behaviors that can cause HIV infection, and other sexually transmitted diseases, unintended pregnancies, and engaging in behaviors that can result in violence or unintentional injuries (Allensworth \& Kolby, 1987). Four of these behaviors, tobacco and alcohol use, unhealthy eating, and inadequate physical activity, contribute to chronic diseases such as cardiovascular disease, cancer, and type 2 diabetes (CDC, 2009).

Young people are clearly at risk. According to the CDC, every day nearly 5,000 young people try their first cigarette. In 2001 , only $32 \%$ of high school students participated in daily physical education classes, compared with $42 \%$ of students in 1991 . Seventy nine percent of young people do not eat the recommended five servings of fruits and vegetables each day; each year, more than 900,000 adolescents become pregnant, and about three million become infected with a sexually transmitted disease (CDC, 2006). The "ideal time" to promote healthy lifestyle trends is during childhood and adolescence, the K-12 school years (Allensworth \& Kolbe, 1987). The notion of teaching standardized, integrated $\mathrm{K}-12$ curriculum were meant to minimize at risk behaviors in young people, by assisting them with developing newly acquired knowledge and skills in health. Figure 1 shows the percentage of states, districts, and schools that require teaching tobacco use prevention by school level. Figure 2 shows the percentage of states, districts, and schools 
that require teaching physical activity and fitness not in physical education by school level.

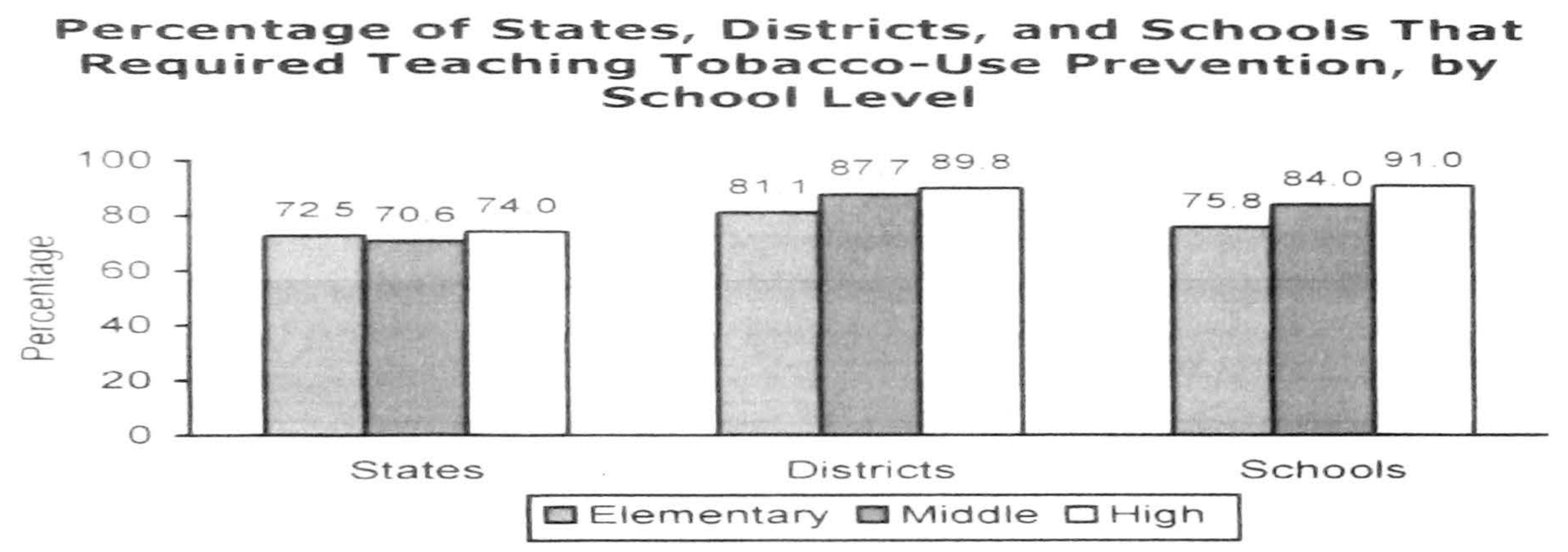

Figure 1. 2006 School Health Policies and Programs Study Data. Adapted from Centers for Disease Control and Prevention (2009). School Health Policies and Programs Study 2009. Healthy Youth.
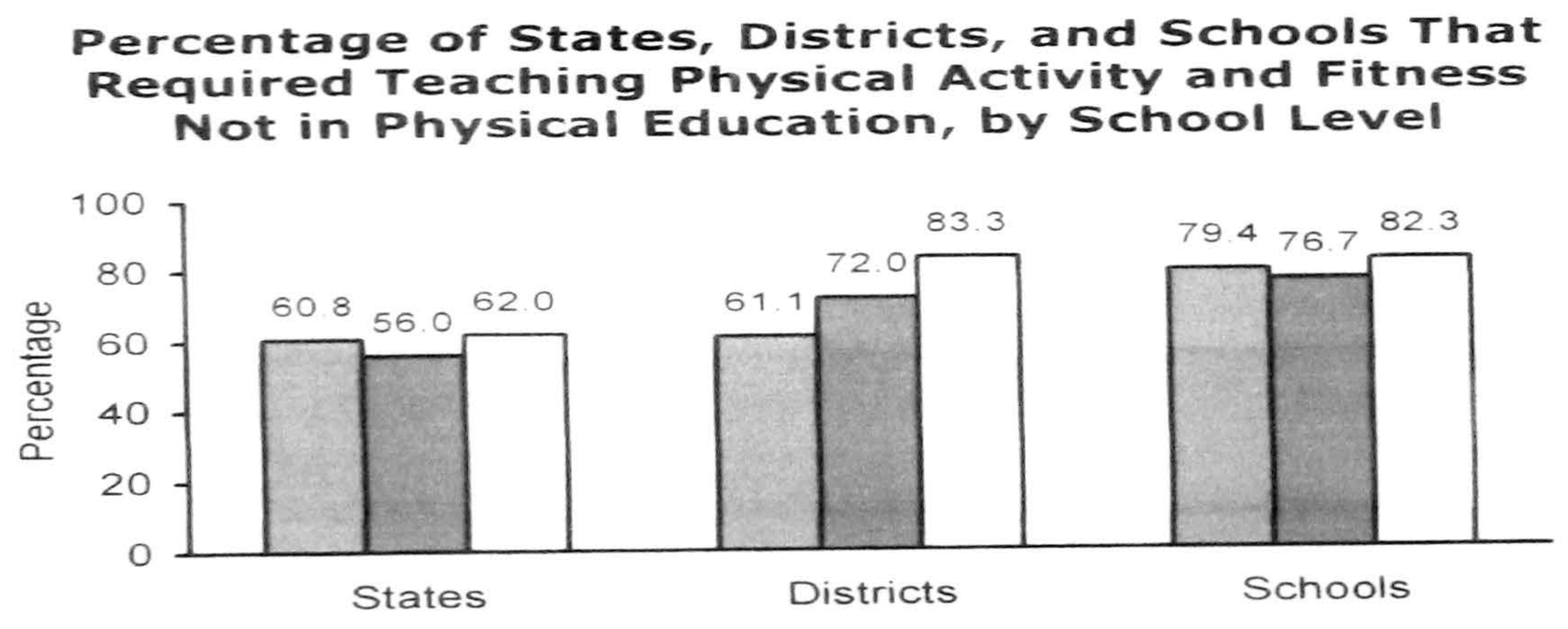

$\square$ Elementary $\square$ Middle $\square$ High

Figure 2. 2006 School Health Policies and Programs Study Data. Adapted from Centers for Disease Control and Prevention (2009). School Health Policies and Programs Study 2009. Healthy Youth. 


\section{Relationship between Risk Behaviors \& Academic Achievement}

Through the national Youth Risk Behavior Survey (YRBS), CDC monitors student health-risk behaviors and the extent to which these behaviors are associated with academic achievement (CDC, 2009). There is a negative association between health-risk behaviors and academic achievement among high school students after controlling for sex, race/ethnicity, and grade level. This means that students with higher grades are less likely to engage in health-risk behaviors than their classmates with lower grades, and students who do not engage in health-risk behaviors receive higher grades than their classmates who do engage in health-risk behaviors (CDC, 2009). These associations do not prove causation. Further research is needed to determine whether low grades lead to health-risk behaviors, health-risk behaviors lead to low grades, or some other factors lead to both of these problems.

The following charts represent the percentages of high-risk behaviors in tobacco use, unhealthy eating and physical activities that contribute to poor youth health and educational outcomes. Figure 3 indicates that $16 \%$ of high school students with mostly As smoked cigarettes, cigars, cigarillos, or little cigars; or used chewing tobacco, snuff, or dip, and $52 \%$ of high school students with mostly Ds/Fs, smoked cigarettes, cigars, cigarillos, or little cigars; or used chewing tobacco, snuff, or dip on at least 1 day during the 30 days before the survey (CDC, 2009). 


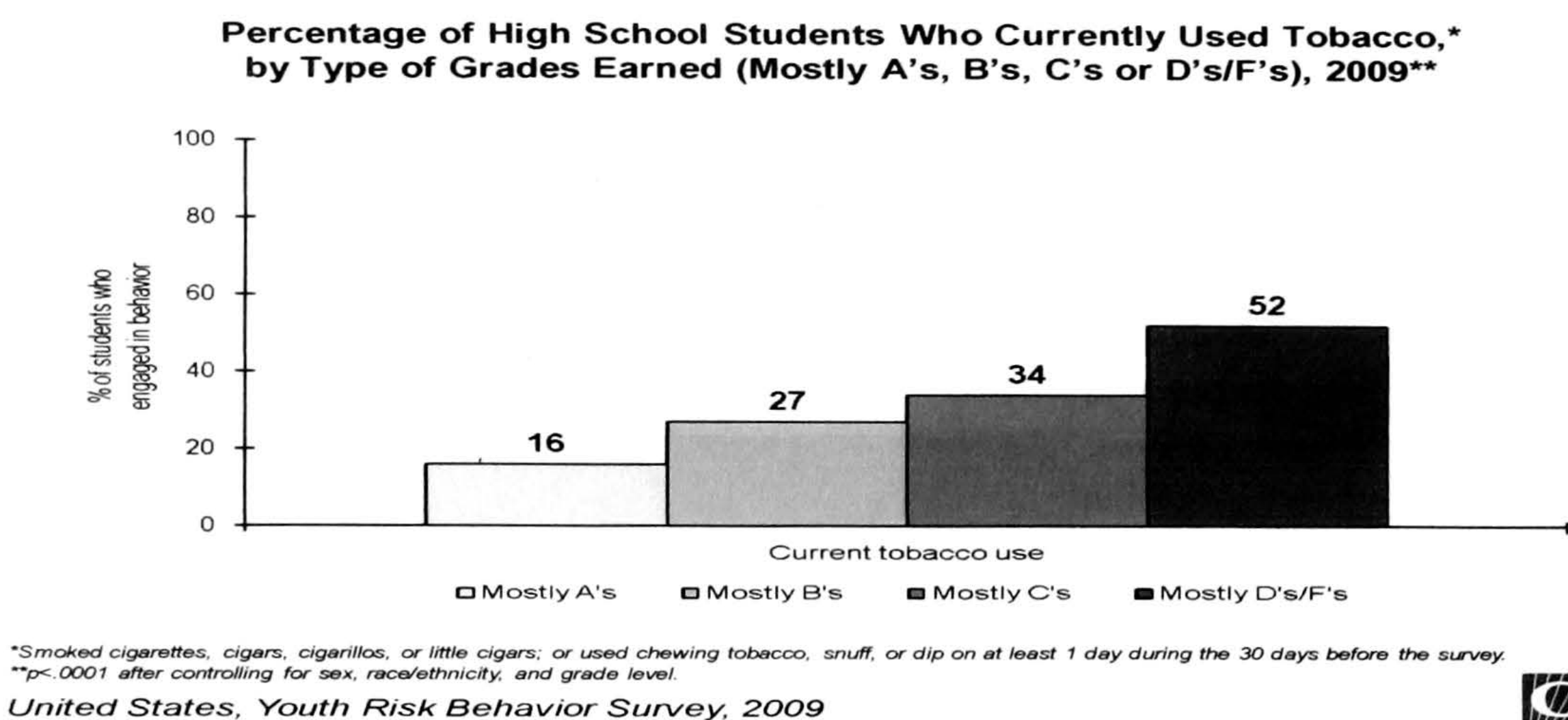

United States, Youth Risk Behavior Survey, 2009

Figure 3. Percentage of High School Students Who Currently used Tobacco by Type of Grades. Adapted from Centers for Disease Control and Prevention (2009). School Health Policies and Programs Study 2009. Healthy Youth.

The table below shows the percentages of unhealthy, high caloric beverages, consumed in a day by high school students. Figure 4 indicates that $22 \%$ of high school students with mostly As drank a can, bottle, or glass of soda or pop (not including diet soda or diet pop) at least one time per day, and $47 \%$ of high school students with mostly Ds/Fs drank a can, bottle, or glass of soda or pop (not including diet soda or diet pop) at least one time per day during the 7 days before the survey (CDC, 2009).

Figure 4. Percentage of High School Students Who Drank a Can, Bottle or Glass of Soda at Least One Time Per Day. Adapted from Centers for Disease Control and Prevention (2009). School Health Policies and Programs Study 2009. Healthy Youth.

The following graph illustrates the percentage of high school students who are physically active for at least 60 minutes a day. Figure 5 indicates that $56 \%$ of high school students with mostly A's were physically active at least 60 minutes per day on less than 5 
days, and $76 \%$ of high school students with mostly Ds/Fs were physically active at least 60 minutes per day on less than 5 days during the 7 days before the survey (CDC, 2009).

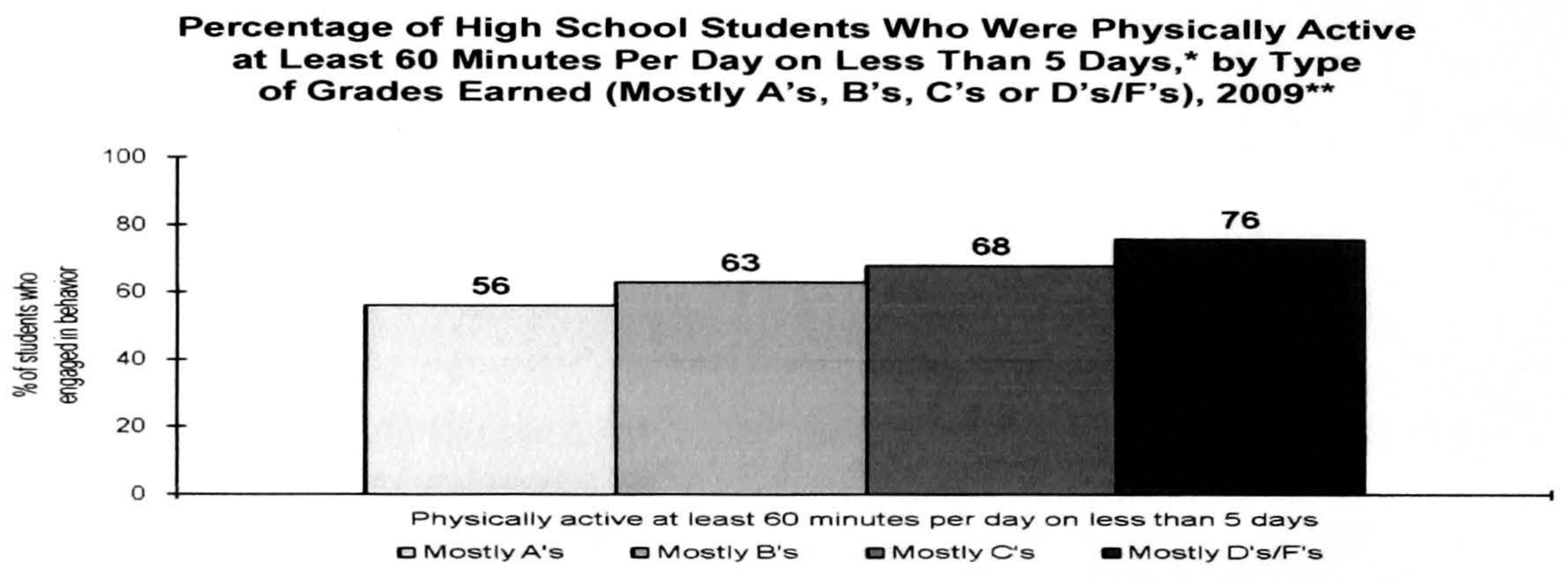

"Any kind of physical activity that increased their heart rate and made them breathe hard some of the time on less than 5 days "-p<.0001 after controlling for sex, race/ethnicity, and grade level.

United States, Youth Risk Behavior Survey, 2009

Figure 5. Percentage of High School Students Who Were Physically Active at Least 60 Minutes Per Day on Less Than 5 Days, by Type of Grades Earned. Adapted from Centers for Disease Control and Prevention (2009). School Health Policies and Programs Study 2009. Healthy Youth.

\section{Staff Development in Health Education}

Since 1992, CDC has funded states, territories, and large urban school districts to help schools implement coordinated health programs. The CDC has also encouraged these states to focus especially on preventing heart disease, cancer, stroke, diabetes, and other chronic diseases by reducing tobacco use, poor nutrition, physical inactivity, and obesity among youth (CDC, 2009). CDC works with other federal agencies, national nongovernmental organizations, and state and local departments of education, health, and social services to plan and implement school health programs. For example, in fiscal year 
2007, the Division of Adolescent and School Health (DASH) spent $\$ 14$ million in support of coordinated school health programs and another $\$ 42$ million in support of HIV prevention education throughout the nation (CDC, 2006).

An important component in acquiring health expertise stems from ongoing teacher professional development on a variety of topics. The percentage of schools that required newly hired health education staff to be certified, licensed, or endorsed by the state in health education increased from $35.0 \%$ in 2000 to $45.9 \%$ in 2006 (CDC, 2006). Approximately $19 \%$ of states required elementary school students to be tested on health topics, and $21.6 \%$ of states required this for middle school and high school students (CDC, 2006). The percentage of states that provided funding for staff development or offered staff development on physical activity and fitness to those who teach health education increased from $68.8 \%$ in 2000 to $82.4 \%$ in $2006 ; 74.0 \%$ of states and $89.8 \%$ of districts provided funding for staff development or offered staff development on tobacco-use prevention to those who teach health education (CDC, 2006).

Professional development is critical to supporting effective teaching and learning. Professional development allows teachers of health and other subjects to: stay up-to-date in their field; learn about and be able to teach effective curricula; gain skills for providing high quality, engaging, standards-based, instruction; improve their ability to conduct valid assessment of students and more (RIDOE, 2008). In Rhode Island (RI), the Thrive e-Academy was launched in 2004 to provide flexible, online professional development opportunities primarily for RI Teachers of Health (health teachers, health/physical education teachers, school nurse teachers and general classroom teachers who teach 
health) (RIDOE, 2008). Each program provides in-depth training on key topics and offers teachers the opportunity to review relevant materials, participate in structured learning activities, and contribute to facilitated discussions with their peers and RIDE staff. Programs vary in length and offer up to 30 teacher professional development contact hours; some programs offer nursing or other CEUs. All programs are free of charge.

\section{Health Programs}

School health programs can play a unique and important role in the lives of youth by helping improve their: health-related knowledge; attitudes; and skills; healthy behaviors and health outcomes; education outcomes; and social outcomes. A highquality school health program is a coordinated and comprehensive set of courses, services, practices, and policies that meet the health and safety needs of students and school staff in kindergarten through grade 12 (Hoyle, Bartee, \& Allensworth, 2010).

The essential elements of an effective school health program include eight interrelated components, many of which already exist to some extent in most schools: health education; physical education and activity; health services; mental health and social services; nutrition services; healthy and safe school environment; faculty and staff health promotion; and family and community involvement (CDC, 2006).

In recent decades, the field of school health has been guided by what has been known as the Coordinated School Health Program (CSHP) model (Means, 1975). In 1987, Allensworth and Kolbe (1987) provided an "expanded" perspective, encouraging linkages and coordination among a broader number of supports to ensure achieving 
healthy, educated students. A coordinated school health program provides a framework for school districts and schools to use in organizing and managing school health initiatives. It also provides an organizational framework for state agencies to use in planning and coordinating school health initiatives, synchronizing comparable public health and school health programs, and efficiently using multiple funding sources to improve the health and education of young people (RIDOE, 2008).

Healthy People 2010 outlined 467 national health objectives, of which 107 are directed specifically toward adolescents and young adults (i.e., 10- to 24-year-olds) (U.S Department of Health and Human Services, [USDHHS], 2010).

Among these 107 objectives, 21 are identified as "critical" based on two criteria: 1) they involve critical health outcomes or behaviors that contribute to them, and 2) state-level data necessary to measure progress in reducing health risks (USDHHS, 2010).

\section{RI School Health Education}

In August, 1995, a diverse group of educators, parents, health professionals, Department of Education staff, and other RI community members gathered as a task force to begin to create a Health Education Framework for the school districts in the state (RIDOE, 2008). The vision for health education in RI is a comprehensive, sequential kindergarten through grade 12 program, hopefully resulting in students who choose to live healthy lifestyles.

For the next several months, the committee thoroughly reviewed those issues that significantly impact our childrens' health, and in turn, impede their ability to succeed as students. Through a series of highly interactive work sessions, the task force discussed 
educational reform and its impact on teaching, learning, and assessment; reviewed and assessed materials; and wrote, discussed, and re-wrote this document to ensure a thorough and meaningful framework (RIDOE, 2008). The task force envisioned what health education might look like when this vision is a reality. The task force believed that: health should be recognized as a core content area in the curriculum, on a level with science and mathematics; daily health education activities should be taught by qualified health educators; school and community must advocate for the crucial role or health education; schools must be safe and healthy; adults in schools are modeling healthy behaviors; parents are involved in student health education curricula and activities; the community serves as a resource and reinforcement of health education areas (RIDOE, 2008).

School health education has been defined in various, though similar ways. For example, $\mathrm{CDC}$ defines health education as a planned, sequential, $\mathrm{K}-12$ curriculum that addresses the physical, mental, emotional, and social dimensions of health (CDC, 2009). Health education is required for all students in grades 1-12 according to RI General Laws $\S 16-22-4$ and students should receive an average of 100 minutes per week of health and physical education (RIDOE, 2008). Specific requirements for health education are outlined in Sections 3, 4 and 5 of the Rhode Island Rules and Regulations for School Health Programs. The outline is designed to motivate and assist students to maintain and improve their health, prevent disease, and reduce health-related risk behaviors (RIDOE, 2008). 
Briefly, the curriculum must: be aligned with the National Health Education Standards ; be sequential, developmentally appropriate, and comprehensive for grades K12; be medically accurate; include standards-based goals, objectives, examples of teaching and learning strategies and materials, and assessment; and cover certain required content areas (RIDOE, 2008). These areas include: alcohol, tobacco and other substance abuse; CPR and blocked air passage training; child abuse; community health; consumer health; environmental health; family life and sexuality; HIV/AIDS; human growth and development; mental health; nutrition; physiology and hygiene; prevention and control of disease; physical activity; safety and injury prevention, including suicide prevention; and teen dating violence education areas (RIDOE, 2008). The RI Common Core of Learning Goals align with the National Health Education Standards. The National Health Education standards develop a framework for "world class" health education in the US. Simply, these standards are a framework for schools to use to create an instructional program that will enable their students to become healthy and capable of academic success. The only difference between the RI Common Core of Learning Goals and the national standards are that RI develops "student specific goals" (students' will...) using the national framework as opposed to general national standards, which detail what students should know and be able to do in health education.

To foster the realization of this vision, RI was funded in 1998 by the national CDC to create an infrastructure which would help to develop and support comprehensive school health programs (CSHP) in school districts. This initiative, entitled Thrive, has nine interdependent child-focused components including health education areas (RIDOE, 
2008). The nine components are physical education, health education, health service, family and community involvement, social environment, physical environment, health promotion, nutrition services, and counseling and psychological services areas (RIDOE, 2008). School success and academic achievement are built on a strong foundation of healthy students learning in safe and caring school environments. Thrive makes the connection between health and student achievement. As partners in Thrive, the RIDOE worked to build infrastructure supports with state, school, and community partners to help create safe, healthy, and nurturing schools that reduce barriers to learning (RIDOE).

Aligned with the RIDOE, Thrive has also been successful in effecting legislative and regulatory changes, and in developing and implementing policy as well as standardsbased curriculum areas (RIDOE, 2008). RI has put much effort into garnering support by "informing others about how a coordinated school health program addresses the "whole child' and contributes to a school's mission" (Hoyle et al., 2010, p163). Much of that work has focused on trying to integrate multiple components to achieve health outcomes, and many professionals have contributed to the knowledge base regarding what constitutes quality standards areas (RIDOE, 2008).

In RI, the seven standards for health education state what all RI students should know and be able to do because of $\mathrm{K}-12$ health education. The performance descriptions elaborating the standards suggest how students at various grade levels can demonstrate movement along the continuum to the eventual achievement of each standard. Table 2 identifies the relationship of RI's Common Core of Learning Goals to National Health Education Standards. 
Table 2

The Relationship of Rhode Island's Common Core of Learning Goals to Rhode Island's Health Education Standards

\begin{tabular}{|c|c|c|c|}
\hline Communication & Problem-Solving & Body of Knowledge & Responsibility \\
\hline $\begin{array}{l}\text { Standard } 5 \\
\text { Students will } \\
\text { demonstrate the } \\
\text { ability to use } \\
\text { Interpersonal } \\
\text { communication } \\
\text { skills to enhance } \\
\text { health. }\end{array}$ & $\begin{array}{l}\text { Standard } 4 \\
\text { Students will } \\
\text { analyze the influence } \\
\text { of culture media } \\
\text { technology and other } \\
\text { factors on health. }\end{array}$ & $\begin{array}{l}\text { Standard } 1 \\
\text { Students will } \\
\text { understand the } \\
\text { concepts related to } \\
\text { health promotion and } \\
\text { disease prevention as } \\
\text { a foundation for a } \\
\text { healthy life. }\end{array}$ & $\begin{array}{l}\text { Standard } 3 \\
\text { Students will } \\
\text { demonstrate the } \\
\text { ability to practice } \\
\text { health-enhancing } \\
\text { behaviors and reduce } \\
\text { health risks. }\end{array}$ \\
\hline & $\begin{array}{l}\text { Standard } 6 \\
\text { Students will } \\
\text { demonstrate the } \\
\text { ability to use goal- } \\
\text { setting and decision- } \\
\text { making skills to } \\
\text { enhance health. }\end{array}$ & $\begin{array}{l}\text { Standard } 2 \\
\text { Students will } \\
\text { demonstrate the } \\
\text { ability to access valid } \\
\text { health information and } \\
\text { health promoting } \\
\text { products and } \\
\text { providers. }\end{array}$ & $\begin{array}{l}\text { Standard } 7 \\
\text { Students will } \\
\text { demonstrate the } \\
\text { ability to advocate for } \\
\text { personal family, } \\
\text { community and } \\
\text { environmental health. }\end{array}$ \\
\hline
\end{tabular}

Source: RI Department of Education, 2008

In summary, the "ideal time" to promote healthy lifestyle trends is during childhood and adolescence, the K-12 school years. The notion of teaching standardized, integrated K-12 curriculum were meant to minimize at risk behaviors in young people, by assisting them with developing newly acquired knowledge and skills in health. Although research indicates that students with higher grades are less likely to engage in health-risk behaviors than their classmates with lower grades, further research is needed to determine whether low grades lead to health-risk behaviors. Professional development is critical to 
supporting effective teaching and learning, yet in the past, funding for staff development has been limited to physical activity and tobacco. This leaves little opportunity to expand health educators' scope of practice, and increase knowledge and skills of at risk students. The complexity of school success and academic achievement are built on a strong foundation of healthy students learning in safe and caring school environments, and the hope is that a coordinated school health program will provide structure to integrate multiple components to achieve health outcomes.

Next the framework used for this program evaluation will be presented. The CDC Framework for Program Evaluation in Public Health can guide this investigator in determining whether or not Coordinated School Health Programs have an impact on health behaviors of grades 9-12, and draw attention to achieving the learning goals to RI Health Education Standards. 


\section{Framework}

The purpose of this project is to evaluate the impact of the Coordinated School Health Program model on grades 9-12, using the CDC Framework for Program Evaluation in Public Health, (1999). It is a practical, nonprescriptive framework, designed to summarize and organize essential elements of program evaluation (CDC, 1999). The framework comprises steps in program evaluation practice and standards for effective program evaluation (Appendix A). The CDC framework emphasizes six connected steps that together can be used as a starting point to tailor an evaluation for a particular public health effort (CDC, 1999), including engage stakeholders, describe the program, focus the evaluation design gather credible evidence, justify conclusions, ensure use of evaluation, and share lessons learned (CDC, 1999). Each step will be briefly described and applied to this program development.

Stakeholders can provide input to ensure that the evaluation of a public health surveillance system addresses appropriate questions and assesses pertinent attributes and determine whether its findings will be acceptable and useful. Stakeholders in health education include teachers, administrators, nurses, RI Department of Health (HEALTH), RI Department of Education (RIDOE), health coordinators, students, and parents. HEALTH and RIDOE provided standards and regulations to guide investigative process. Teachers and nurses identified health resources, and taught content areas for the 20082009 academic year. Administrators were responsible for oversight and coordination of survey distribution. Student and parent participation was necessary for survey completion and analyses. 
In relation to describing the program, the Coordinated School Health Program model is designed to be used nationally across the continuum of school health education. The program model consists of eight interactive components, this investigator focused on one interactive component (health education), which focused the design and gathered the evidence. This investigator gathered evidence from two sources, Youth Risk Behavior Surveillance data, which is collected every two years during the spring semester and provides data representative of $9-12$ th grade students, and InformationWorks! surveillance data that is collected annually and provides data representative of $\mathrm{K}-12^{\text {th }}$ grade students (all data is collected from public and private schools in the US). All data is accessible to the public, and conclusions will be based on analyses of YRBS, Information Works! data percentiles, in comparison to Healthy People 2010 target measure percentiles.

For the purpose of this evaluation, written conclusions and recommendations are available for dissemination to interested stakeholders: RIDOE may benefit from this project by way of disseminating program findings to school districts; administrators' gain increased awareness of unmet health topic areas in RI schools; students' obtain need based health knowledge and skills; teachers recognize importance of acquiring evidence based health resources that target specific at risk behaviors, and HEALTH can focus community initiatives on unmet youth health needs.. 


\section{Methodology}

\section{Purpose}

The purpose of this project was to evaluate the impact of Coordinated School Health Program on health behaviors of RI high school students. This was accomplished by analyzing existing health surveillance data from the Youth Risk Behavior Survey and Information Works 2008, and comparing the percentages to Healthy People 2010 target measure percentages. Once completed, the data from this evaluation was compiled and reviewed to determine the areas in which changes could potentially improve the programs currently provided to students in RI high schools.

\section{Design}

Retrospective data was collected from two sources: YRBS 2009, and Information Works! 2008. YRBS is an anonymous and voluntary survey conducted among random samples of high school students, and is the largest public health surveillance system in the US, monitoring a broad range of health-risk behaviors among high school students (CDC, 2009). The CDC's Institutional Review Board approved the protocol for the national YRBS (CDC, 2009). The CDC developed the YRBS to monitor risk behaviors related to the major causes of mortality, disease, injury, and social problems among youth and adults in the US (CDC, 2009). In addition to describing the prevalence of health-risk behaviors, YRBS data is used widely to compare health-risk behavior prevalence among subpopulations of students, assess trends in health-risk behaviors over time, monitor progress toward achieving national health objectives, provide comparable state and local data, and evaluate and improve health-related policies and programs (CDC, 2009). 
The YRBS 2009 standard questionnaire contains 87 questions; states and cities can add or delete questions from the standard questionnaire (Appendix B). In year 2009, 16,460 questionnaires were completed in 158 schools (CDC, 2009). The national data set was cleaned and edited for inconsistencies. Each state and local school-based survey used a two-stage cluster sample design to produce a representative sample of public school students in grades 9-12 in their jurisdiction. In the first sampling stage, schools with any of grades $9-12$ were sampled with probability proportional to school enrollment size in 40 states and six cities; all schools with any of grades 9-12 were sampled in two states and 14 cities (CDC, 2009). RI used the YRBS 2009, standard 87-question questionnaire (RIDOE, 2008).

In the second sampling stage, in 41 states and 20 cities, intact classes from either a required subject were sampled randomly, and all students in the sampled classes were eligible to participate (CDC, 2009). Before survey administration, local parental permission procedures were followed. Students completed the self-administered questionnaire during one class period and recorded their responses directly on a computer-scannable booklet or answer sheet.

CDC has conducted two test-retest reliability studies of the national YRBS questionnaire, one in 1992 and one in 2000. In the first study, the 1991 version of the questionnaire was administered to a convenience sample of 1,679 students in grades 712. The questionnaire was administered on two occasions, 14 days apart (CDC, 2004). Approximately three fourths of the items were rated as having a substantial or higher reliability $($ kappa $=61 \%-100 \%$ ), and no statistically significant differences were 
observed between the prevalence estimates for the first and second times that the questionnaire was administered (CDC, 2004).

In the second study, the 1999 version of the questionnaire was administered to a convenience sample of 4,619 high school students (CDC, 2004). The questionnaire was administered on two occasions, about two weeks apart. Approximately one of five items $(22 \%)$ had significantly different prevalence estimates for the first and second times that the questionnaire was administered (CDC, 2004).

Ten items (14\%) had both kappas $<61 \%$ and significantly different time- 1 and time-2 prevalence estimates, indicating that the reliability of these items was questionable (CDC, 2004). Certain items (e.g., an item related to injury during physical activity) have been revised for or deleted from later versions of the questionnaire (CDC). For purpose of this project, RI high school student data (grades 9-12) will be examined for 2008-2009.

Information Works! 2008-2009 was developed through a partnership between the RI Department of Elementary and Secondary Education and the National Center on Public Education and Social Policy, at the University of Rhode Island. Information Works consists of a set of school report cards, a set of district report cards, and the state report card. Information Works! includes data from a variety of sources (RI Department of Education, 2008). School health-related data are derived from the School Accountability for Learning and Teaching (SALT) student survey data, which include questions on alcohol, tobacco and other drug use, sleep, nutrition, physical activity, and the school environment and climate. In RI, there were 151,619 students, K-12 grade, who participated in 2008 SALT survey data (RIDOE, 2008). The surveys were distributed 
during regular school days, and students who were absent on those days did not participate.

Reliability analyses were conducted to examine the internal consistency in student responses using coefficient alpha statistics (Cronbach, 1951). Cronbach's coefficient alpha statistics for eight behavioral scales showed moderate to high levels of internal consistency for 2008-2009 SALT survey data. No study has been conducted to assess the validity of all self-reported behaviors that are included on YRBS questionnaires and SALT surveys. However, in 2003, CDC conducted a review of existing empirical literature to assess cognitive and situational factors that might affect the validity of adolescent self-reporting of behaviors measured by questionnaires and surveys (CDC, 2004). In this review, CDC determined that, although self-reports of these types of behaviors are affected by both cognitive and situational factors, these factors do not threaten the validity of self-reports of each type of behavior equally. In addition, each type of behavior differs in the extent to which it can be validated by an objective measure (CDC, 2004). For example, reports of tobacco use are influenced by both cognitive and situational factors and can be validated by biochemical measures (e.g., cotinine). Reports of physical activity, in contrast, are influenced substantially by cognitive factors but to a lesser degree by situational ones. Such reports can be validated by mechanical or electronic monitors (e.g., heart rate monitors). For purpose of this project, RI high school student data (grades 9-12) will be examined for 2008-2009. 


\section{Procedures}

For the purpose of this evaluation, the investigator focused on four areas within the health education component (tobacco, alcohol use, unhealthy eating, and inadequate physical activity), and by comparing the YRBS 2009, and Information Works! 20082009 data percentages, to the Healthy People 2010 (HP) target measures.

Youth Risk Behavior Survey and Information Works! survey data were collected exclusively in relation to the four topic areas. These topic areas are consistent with RI Health Standard Number Three: Students will demonstrate the ability to practice healthenhancing behaviors and reduce health risks. Some objectives seek to increase positive behaviors or outcomes while others are stated in terms of decreasing negative behaviors or outcome. The percentage comparisons from each data source and topic area will suggest if students at grade levels 9-12 have demonstrated movement along the continuum to the prospective achievement of HP 2010 target measures.

All data collected was public information. Data was accessed on the YRBS, Healthy People 2010, and InformationWorks! websites. Investigator focused on trends in high risk behaviors among $9-12^{\text {th }}$ grade RI students for the year 2009, collected outcome percentages of specific data (tobacco, alcohol use, unhealthy eating, and physical activity), and compared outcomes to Healthy People 2010 target percentiles.

\section{Analysis}

The outcomes were measured using a Healthy People 2010 process quotient. The progress quotient $(\mathrm{PQ})$ measures the percent of the targeted change that was achieved (USDHHS, 2010). It is a relative measure because it expresses any change between the 
baseline and the most recent value as a percentage of the difference between the baseline and the 2010 target. The comparability of the PQ does not depend on whether the measure is expressed in terms of adverse or positive outcomes. Data beyond the baseline are available for about $53 \%$ of the objectives and sub-objectives in Healthy People 2010 (USDHHS). Most recent YRBS and Information Works! values was analyzed in comparison to HP 2010 baseline data, and measured in percentages. The formula for the PQ is indicated below.

Percent of targeted change achieved $=\left(\frac{\text { Most recent value }- \text { baseline value }}{\text { Year } 2010 \text { target }- \text { baseline value }}\right) \times 100$ 


\section{Results}

Table 3 shows percentages of health risk behaviors by gender in comparison to Healthy People 2010 Target Measures for the year 2009. Nationally, 33.9\% of students had eaten fruit or drunk 100\% fruit juices two or more times per day during the 7 days before the survey (CDC, 2009). In RI, the prevalence of having eaten fruit or drunk 100\% fruit juices two or more times per day was higher among male $(36.3 \%)$ than female (33.5\%) students, not meeting HP target of (75\%). Nationwide, $22.3 \%$ of students had eaten fruits and vegetables five or more times per day during the 7 days before the survey (CDC, 2009). Locally, the prevalence of having eaten fruits and vegetables five or more times per day was higher among male (13.6\%) than female $(12.1 \%)$ student, not meeting HP target of (50\%); based on nationwide data, differences in healthy eating comparisons are not seen as surprising. 
Table 3.

Rhode Island Health Risk Behaviors by Gender Compared to Healthy People Target Measures

\begin{tabular}{|c|c|c|c|c|}
\hline Variable & Female & Male & $\begin{array}{l}\% \text { Avg. } \\
\text { Target }\end{array}$ & $\begin{array}{l}\text { HP } \\
\text { Target }\end{array}$ \\
\hline \multicolumn{5}{|c|}{2009 Youth Risk Behavior Survey } \\
\hline \multirow[t]{2}{*}{ Healthy Eating } & $33.5 \%$ & $36.3 \%$ & $34.9 \%$ & $75 \%$ \\
\hline & $12.1 \%$ & $13.6 \%$ & $12.9 \%$ & $50 \%$ \\
\hline \multirow[t]{2}{*}{ Tobacco } & $8.0 \%$ & $8.8 \%$ & $8.4 \%$ & $14 \% *$ \\
\hline & $13.2 \%$ & $13.3 \%$ & $13.3 \%$ & $16 \% *$ \\
\hline \multirow[t]{2}{*}{ Alcohol } & $15.4 \%$ & $16.8 \%$ & $16.1 \%$ & $16.1 \% *$ \\
\hline & $35.6 \%$ & $32.2 \%$ & $34 \%$ & $8.0 \%$ \\
\hline \multirow[t]{2}{*}{ Physical Activity } & $16.9 \%$ & $16.5 \%$ & $16.7 \%$ & $5 \%$ \\
\hline & $34.9 \%$ & $52.8 \%$ & $44 \%$ & $35 \% *$ \\
\hline
\end{tabular}

2008-2009 Information Works!

Female/Male Minimum Maximum range range

Healthy Eating

$46 \%$

$52 \%-73 \%$

Tobacco

$23 \%$

$8 \% \quad-\quad 35 \% *$

Alcohol

$38 \%$

$13 \%-25 \%$

Physical Activity

$43 \%$

$17 \%-28 \%$

Adapted from 2009 Youth Risk Behavior Survey, 2008-2009 Information Works!

* Healthy People 2010 goal met or with-in range. 
Generally, $10.7 \%$ of students had smoked a whole cigarette for the first time before age 13 years (CDC, 2009). In RI, the prevalence of having smoked a whole cigarette before age 13 years was higher among male $(8.8 \%)$ than female $(8 \%)$, meeting the HP target of (14\%). Nationwide, $26.0 \%$ of students had reported current cigarette use, current smokeless tobacco use, or current cigar use (CDC, 2009). Locally, the prevalence of current tobacco use was higher among male (13.3\%) than female (13.2\%), meeting HP target of $(16 \%)$; based on nationwide data, similarities in tobacco use are not seen as unusual.

In the US, $41.8 \%$ of students had had at least one drink of alcohol on at least 1 day during the 30 days before the survey (CDC, 2009). In RI, the prevalence of current alcohol use was higher among female $(35.6 \%)$ than male $(32.2 \%)$ students, not meeting HP target of ( $8 \%$ ); based on nationwide data, differences in alcohol use are not seen as surprising.

On a national scale, $15.8 \%$ of students were overweight or obese (CDC, 2009). In RI, the prevalence of overweight or obese was higher among female (16.9) than male (16.5), not meeting HP target of (5\%); although $52 \%$ of males compared to $34.9 \%$ of females are engaging in at least 30 minutes of exercise 5 days a week, exceeding HP target of (35\%); based on nationwide data, differences in physical activity comparisons are not seen as surprising. In sum, it is clear that healthy eating, physical activity and alcohol had the largest percentile differences, while tobacco had the smallest percentile differences. 


\section{Summary and Conclusions}

Young people are continuously at risk for developing a range of high risk behaviors. Our nations young people are at risk and the seriousness of the health risks endanger young people and their ability to achieve optimal health and wellness. Health education within the public school system is a primary source of prevention for developing young people. The range of unmet HP 2010 target measures (in alcohol use, unhealthy eating, and inadequate physical activity) may explain why coordinated health programs as envisioned by the model have not become a sustainable reality in many local communities.

In analyzing the 2009 Youth Risk Behavior Survey, this reviewer identified two areas (tobacco and alcohol), which met HP 2010 target measures. In RI, the prevalence of having smoked a whole cigarette before age 13 years was higher among male $(8.8 \%)$ than female $(8 \%)$ students, the HP 2010 target of $(14 \%)$ was met in this age category; prevalence of current cigarette use was higher among males $(13.2 \%)$ than females (13.3\%), the HP 2010 target of (16\%) was met. Results could be accredited to Rhode Islands’ 2004 enactment of the Rules and Regulations Pertaining To Smoke-Free Public Places and Workplaces [R23-20.10-Smoke]. RI also uses multiple strategies to reduce: smoking; exposure to second-hand smoke; and use of other tobacco products. The regulation assisted community programs with changing the social and physical environment. Now, It is more difficult to start and continue using tobacco, since the regulation made it easier to quit, and made choosing health the easier choice. 
From a political standpoint, Rhode Island has the highest state cigarette tax $(\$ 3.46$ per pack) in the nation, the private insurance mandate to cover cessation services was passed, and state Medicaid coverage of recommended cessation medications was approved. Since these changes took place, fewer Rhode Islanders smoke. The youth smoking rate dropped from $25 \%$ to $15 \%$ and the adult smoking rate from $23 \%$ to $17 \%$ (HEALTH, 2010).

In RI, the prevalence of having drank alcohol before age 13 years was higher among males (14.8\%) than females (14.4\%) students, and the HP 2010 target of (16.1\%) was met; conversely, the percentage of high school students who currently drink alcohol was higher among females (35.6\%) than males $(32.2 \%)$ students, the HP $(8 \%)$ target measure was not met. Alcohol is one of the most widely used drug substances in the world. In the U.S. 10.8 million underage persons 12 to 20 (28.7\%) reported drinking alcohol in the past month. Alcohol use and binge drinking among our nation's youth is a major public health problem: Alcohol is used by more young people in the United States than tobacco or illicit drugs. Excessive alcohol consumption is associated with approximately 75,000 deaths per year (CDC, 2006). According to the National Survey of Substance Abuse Treatment Services (N-SSATS), in March 2009, there were 524 Rhode Islanders' under the age of 18 , in either inpatient or outpatient treatment for alcohol abuse. Alcohol abuse is one of our nations targeted health disparities for youth under 18 years of age (USDHHS, 2010).

Rates of drinking differ among racial and ethnic minority groups. Among students in grades 9 to 12 , binge drinking was reported by 34 percent non-Hispanic white 
students. 11 percent of African American students, and 30 percent of Hispanic students (USDHHS. 2010). One of the implications of this is that many young people under the age of 18, of ALL ethnicities are involving themselves in alcohol abuse. This is an important consideration when the topic of teen alcoholism and alcohol abuse is raised. At the societal level, distal costs follow from proximal opportunities that were missed to intervene and reduce burden of illness. For example, liver disease may result from longstanding poorly controlled alcoholism. The highly morbid and highly costly condition could potentially be avoided with effective health education and access to age appropriate, culturally relevant preventative services.

Locally, the prevalence of having eaten fruit or drunk $100 \%$ fruit juice two or three times per day was higher among males $(36.3 \%)$ than females $(33.5 \%)$ students, falling moderately far from the HP (75\%) target measure. The prevalence of having eaten fruits and vegetables five or more times per day was higher among male (24\%) than female (21.3\%) students, falling comparatively far from the HP (50\%) target measure.

Nutrition education also should focus on preventing children and adolescents from developing chronic diseases during adulthood. Some of the physiological processes that lead to diet-related chronic disease begin in childhood. For example, hardening of the arteries that is the most common cause of coronary heart disease [CHD] begin in youth, and are related to high blood cholesterol levels in young persons. Unhealthy eating practices that contribute to chronic disease are established early in life; young people who have unhealthy eating habits tend to maintain these habits as they age. Thus, it is 
efficacious to teach young people healthy eating patterns when they are young, because high-risk eating behaviors and physiological risk factors are difficult to change once they are established during youth.

In RI, prevalence of being overweight was higher among female $(16.9 \%)$ than male $(16.5 \%)$ students; significant difference from the HP $(5 \%)$ target measure. The prevalence of having been physically active for at least 30 minutes per day on 5 or more week days was higher among male (52.8.\%) than female (34.9\%) students, males met HP (35\%) target measure, and females did not meet target by a tenth of a percentage point.

Positive results in increasing physical activity could have an association with the age group (14-19) as it relates to changes in high school students, and national initiatives to increase physical activity. High school students tend to be more involved in extracurricular activities, community and school sports, and are socially engaged in peer activities. Especially males in minority groups who view sports as an outlet for nervous tension in their communities, regularly seeking opportunities to play sports, coupled with hope and drive to play professionally (media overload). Sadly enough, less than $1 \%$ of minority males will play sports professionally, but the hope of becoming the next NBA/NFL player keeps them physically driven.

\section{Limitations}

There are several limitations that prevent a more conclusive interpretation. They include: First, these data apply only to youth who attend school and, therefore, are not representative of all persons in this age group. Nationwide, in 2009, of persons aged 1617 years, approximately $4 \%$ were not enrolled in a high school program and had not 
completed high school (Laird, 2007). Second, the extent of underreporting or over reporting of behaviors cannot be determined, although the survey questions demonstrate good test-retest reliability (Brener, 2002). Third, BMI is calculated on the basis of selfreported height and weight, and. therefore, tends to underestimate the prevalence of obesity and overweight (Brener, 2003).

While survey's show coordinated school health education resulting in some positive behavior changes in tobacco use, the difficulty of changing at risk behaviors in the areas of alcohol, healthy eating, and physical activity continues to be a challenge for young people and the community as a whole. The literature points to improving specific knowledge and attitudes about health behaviors in school health programs, but support from community stakeholders can play an integral role in changing behavior. The CDC (2006) adolescent health division recommends societal influences on adolescent behavioral change as comprising:

1. Influencing behavior change at the individual, peer, family, school, community, and societal levels. Because many sectors of society contribute to adolescent health, safety, and well-being, a collaborative effort that engages multiple partners is necessary.

2. Promote a more comprehensive approach to addressing adolescent health, one that views each adolescent as a whole person, recognizing and drawing upon his or her assets and not just focusing on risks. 
3. To have the most positive impact on adolescent health, government agencies, community organizations, schools, and other community members must work together in a comprehensive approach.

4. Provide safe and nurturing environments for our nation's youth can help ensure that adolescents will be healthy and productive members of society.

This perspective, which focuses on the most positive impact on adolescent health, emphasizes the need for government agencies, community organizations, schools, and other community member to work together in a comprehensive approach. Providing safe and nurturing environments for our nation's youth can help ensure that adolescents will be healthy and productive members of society.

Research demonstrates relatively high percentages of high risk behaviors in teen alcohol use, unhealthy eating and poor physical activity. High percentages of obesity continue to present huge complications for our health care system. Early indicators of atherosclerosis, the most common cause of heart disease, begins as early as childhood and adolescence. Atherosclerosis is related to high blood cholesterol levels, which are associated with poor dietary habits. Long-term consequences of physical inactivity and poor diet, are significantly associated with an increased risk of diabetes, high blood pressure, high cholesterol, asthma, arthritis, and poor health status (CDC, 2006).

Diet-related risk factors for cardiovascular disease (e.g., high blood cholesterol level, high blood pressure, and overweight) are common in youths in the United States. Compared with their peers, children and adolescents who have high blood cholesterol, have high blood pressure, or are obese are more likely to have these risk 
factors during adulthood. Poor diet and inadequate physical activity together account for at least 300.000 deaths in the United States annually (CDC, 2009). Interventions that promote healthy eating and physical activity behaviors during childhood and adolescence may not only prevent some of the leading causes of illness and death but also decrease direct health-care costs and improve quality of life. Nutrition education also should focus on preventing children and adolescents from developing chronic diseases during adulthood.

The US has recognized the influence media has on our youth and has encouraged initiatives to increase physical activity and healthy eating. U.S. Rep. Ron Kind (D-WI) and U.S. Senator Tom Harkin (D-IA) reintroduced the Fitness Integrated with Teaching Kids Act (FIT Kids Act) this week, a bill to combat childhood obesity by strengthening physical education programs in schools throughout the country (Harkin.gov, 2011). In conjunction with the President's Council on Fitness, Fuel Up to Play 60 is an in-school program that encourages the availability and consumption of nutrient-rich foods, along with at least 60 minutes of daily physical activity. Created in partnership by National Dairy Council (NDC) and the National Football League (NFL), Fuel Up to Play 60 empowers youth to take action to improve nutrition and physical activity at their school and for their own health. The ultimate goal is to ensure changes made at school are sustainable so children have more opportunities to be physically active. Nationwide, $66 \%$ of schools are participating in Play 60, and In RI, 259 schools participated in the 20092010 academic year (National Dairy Council, 2010). Fuel Up to Play 60 continues to 
make huge advances across the nation. but additional statistics will need to be gathered to determine viable outcomes.

Although, the promise of a Coordinated School Health Program is encouraging, the model seems disjointed. In this reviewers school, administrative support for school health has not been defined. There does not appear to be "one" standard health curriculum that is utilized by all health educators in the RI public school system. One standardized, evidenced based curriculum, utilized and measured across all school districts, could more effectively analyze health literacy and evaluate performance outcomes in RI schools.

Professional collaborative efforts govern successful education. Deficiencies in coordination and consensus is often attributed to an additional need for funding, limited resources, individual time restraints, and an overall lack of urgency to hire "qualified" health educators (licensed nurse or certified health educator). According to Allensworth \& Kolby, skill-development in health content and coordination are necessary; integrating health throughout the academic curriculum has been given poor guidance regarding how coordination across all components might occur'; no districts appear organized to align with or accommodate the eight component model (Allensworth, Kolby,1987, p412).

There has been some positive behavior changes, but there is much work to be done on a national level to ensure that our youth are provided with the tools needed to make informed health decisions. Unhealthy behaviors become habits, so changing them can be very difficult. They are more likely to make changes in their habits if they set a specific goal for themselves, focus on one high-risk behavior at a time, increase their 
knowledge base, and decrease the likely hood of societal exposure (Marx, et al., 1998). These messages must be heard throughout the community as a whole. We are all products of our environments, and in some cases, individuals live where they can afford to live. Given these circumstances, vulnerable populations should not be subjected to a poorer quality of health education, the outcomes affect everyone. So, when do we begin to collectively come together and address the high-risk behaviors of young people throughout our nation? 


\section{Recommendations and Implications for Advanced Practice Nursing}

Advanced Practice Nurse (APN) could suggest an "active, systematic process," understanding how things influence one another within a whole (Answers Corporation, 2010). Approaching health promotion from a community driven or ecological perspective, which identifies multiple community stakeholders' and evidence based best practice and goal based interventions. APN's could lead community driven efforts for multifaceted data compilation that are generated from diverse sources of data, and useful in determining community health needs. For example, nutrition education presents opportunities for young people to learn about and experience cultural diversity related to food and eating. Students from different cultural groups have different health concerns, eating patterns, food preferences, and food-related habits and attitudes. APN's acquire knowledge in cultural awareness, and would consider these differences when designing lesson plans or discussing food choices. APN's recognize thatnutrition education can succeed only when students believe it is relevant to their lives.

APN's could compile data to identify and access much needed funding for resources in the community (school materials, grass root programs, health clinics, etc...) APN's could help implement evidenced based health promotion activities that are geared toward achieving successful outcomes. APN's can provide professional development that is specific to health education, and can do research to identify the correlation to primary prevention (recruit licensed/certified professionals to develop curriculum and teach health education to students). APN's should be recognized as experts in health education, scholars in evidenced based best practice, and utilize their expertise in all phases of 
curriculum development, teaching, and program evaluation. Lastly, APN's could develop health education policies that identify national standardized health curriculum that is age appropriate, culturally relevant, and based on current health risk trends. As health experts, APN's realize that health curriculums should also be student driven, outcome based and integrated throughout all academic curriculums.

The Centers for Disease Control and Prevention Framework for Program Evaluation in Public Health suggests gathering credible evidence, justifying conclusions, sharing lessons learned, and most importantly, conducting process and formative evaluations to monitor implementation and to refine and improve programming to assure progress and success (CDC, 1999).

Consistency with school and community improvement processes, and health promotion could be integrated into the fabric of schooling and society as a whole. APN's must apply what they know to be an effective change process that addresses educational, social, and quality of life outcomes (Hoyle, et al., 2010). Furthermore, APN's must immediately respond to the expressed need for "specific and concrete skill development on how to execute this process in the school setting; it is the application of processoriented leadership skills by competent, appropriately prepared school health professionals that will enhance the viability and solidify the niche of "school health" in the educational setting (Hoyle, Bartee, Allensworth, 2010, p168). Enhancing quality of life and positively changing social indicators are ultimate desired outcomes of health education and promotion. This emphasis on health, social, economic, and other environmental factors as determinants of students' readiness to learn gives credence to 
"school health" as a vehicle for accomplishing the mission of schooling (Hoyle, et al., 2010). 


\section{References}

Allensworth DD, \& Kolbe LJ, (1987). The comprehensive school health program:

Exploring an expanded concept. Journal of School Health. 1987;57:409-412. doi: $10.1111 / \mathrm{j} .1746-1561.1987 . t b 03183 . x$

Answers Corporation, (2010). WikiAnswers.

http://wiki.answers.com/Q/What_is_the_definition_of_systemic_process.

Brener (2002). Reliability of the 2009 Youth Risk Behavior Survey questionnaire.

Journal of Adolescent Health 2002;31:336-42.

Brener (2003). Reliability and validity of self-reported height and weight among high school students. Journal Adolescent Health 2003;32:281-7.

Centers for Disease Control and Prevention, (2006). School Health Policies and Programs Study 2006. Healthy Youth. Retrieved from http://www.cdc.gov/HealthyYouth/shpps/index.htm

Centers for Disease Control and Prevention (2009). Youth Risk Behavior Surveillance. MMWR Surveillance Summary 2009. Retrieved from www.cdc.gov/yrbs.

Centers for Disease Control and Prevention (1999). Framework for Program Evaluation in Public Health. MMWR 1999;48(No. RR-11). Retrieved from http://www.cdc.gov/mmwr/pdf/rr/rr4811.pdf

Centers for Disease Control and Prevention 2004). Methodology of the Youth Risk Behavior Surveillance System. MMWR 2004;53. Retrieved from http://www.cdc.gov/mmwr/preview/mmwrhtml/rr5312a1.htm. 
Cronbach, L., (1951). Coefficient alpha and the internal structure of tests. Psychometrika, 16, 297-334. Retrieved from http://www.garfield.library.upenn.edu/classics1978/A1978EQ39200002.pdf. Harkin, T. (2011). Senator Harkin, Rep. Kind Reintroduce FIT Kids Act, calling for more P.E. in schools. Retrieved from http://harkin.senate.gov/press/release.cfm?i=331890.

Heeb, MA. (2005). The role of schools in healthy people 2000. JAMA, 1995 Oct 18;274(15):1195-6. Retrieved from http://www.ncbi.nlm.nih.gov/pubmed/7563501.

Hoyle, T. B., Todd Bartee, R. and Allensworth, D. D. (2010), Applying the Process of Health Promotion in Schools: A Commentary. Journal of School Health, 80: 163166. doi: 10.1111/j.1746-1561.2009.00483.

Laird J. (2007). Dropout rates in the United States:2004. Washington, DC: US Department of Education, National Center for Education Statistics; 2006. Publication no. NCES 2007-024.

Marx, Wooley, and Northrop (1998). Health Is Academic: A Guide to Coordinated School Health Programs, New York: Teachers College Press, Columbia University.

Means, Richard Ed.D. (1975). Historical Perspectives on School Health. Thorofare, N.J.: Charles B. Slack Inc.

Murray, N. G., Low, B. J., Hollis, C., Cross, A. W. and Davis, S. M. (2007), Coordinated 
School Health Programs and Academic Achievement: A Systematic Review of the Literature. Journal of School Health, 77: 589-600. doi: 10.1111/j.17461561.2007.00238.

National Association of State Boards of Education (2002). Education Reform \& the Goals of Modern School Health Programs. Retrieved from http://www.bvsde.paho.org/bvsacd/cd61/education.

Rhode Island Department of Education (2008). Information Works! 2008 Salt Survey Data. Retrieved from http://www.infoworks.ride.uri.edu/2009/default.asp.

Rhode Island Department of Health (2010). Tobacco Control Program.

Retrieved from http://www.health.state.ri.us/programs/tobaccocontrol/index.php U.S. Department of Health and Human Services (2010). Office of Disease Prevention and Health Promotion. Healthy People 2010-2020.

Retrieved from http://www.healthypeople.gov/.

U.S. Department of Health and Human Services (2010). Substance Abuse \& Mental Health Services Administration. N-SSATS 2009. Retrieved from http://wwwdasis.samhsa.gov/webt/tedsweb/tab_year.choose_year?t_state=RI 


\section{APPENDIX A}

Center of Disease and Prevention Framework for Evaluation in Public Health

\section{Recommended Framework for Program Evaluation}

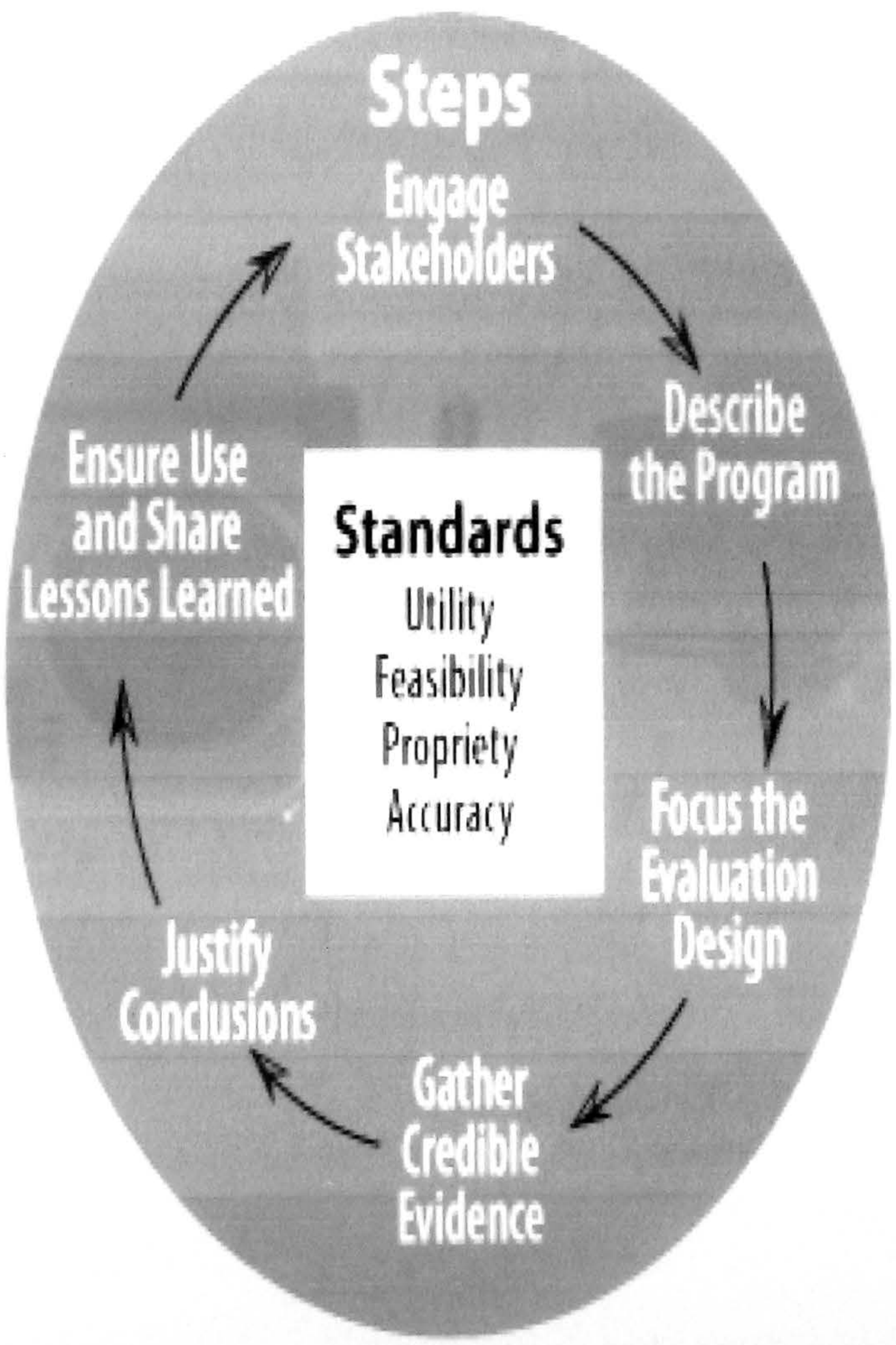

Source: (enters for Disease Control and Prevention.

Framework for Evaluation in Public Health.

MMWR 1999; 48(No. RR-11). 


\section{APPENDIX B}

2009 Youth Risk Behavior Survey \& 2008-2009 Informationworks! Category Descriptions

2009 Youth Risk Behavior Survey

\begin{tabular}{|c|c|}
\hline Healthy Eating & $\begin{array}{l}\text { Percentage of } 12^{\text {th }} \text { high school students who ate fruit or drank } 100 \% \text { fruit } \\
\text { juices two or more times/day. } \\
\text { Percentage of high school students who ate vegetables three or more } \\
\text { times/day }\end{array}$ \\
\hline Tobacco & $\begin{array}{l}\text { Percentage of high school students who smoked a whole cigarette for the } \\
\text { first time before age } 13 \text { years. } \\
\text { Percentage of high school students who currently smoke. }\end{array}$ \\
\hline Alcohol & $\begin{array}{l}\text { Percentage of } 12^{\text {th }} \text { grade students who drank alcohol for the first time } \\
\text { before age } 13 \text { years } \\
\text { Percentage of high school students who currently drink alcohol. }\end{array}$ \\
\hline Physical Activity & $\begin{array}{l}\text { Percentage of high school students who are overweight or obese, } \\
* \text { Students }>95^{\text {th }_{0}} \% \text { by body mass index. } \\
\text { Percentage of high school students who are physically active for at least } \\
30 \text { minutes/day on } 5 \text { or more days }\end{array}$ \\
\hline \multicolumn{2}{|c|}{ 2008-2009 Information Works! } \\
\hline Unhealthy Eating & $\begin{array}{l}\text { Percentage of high school students who say that during the past week } \\
\text { they ate breakfast } 2 \text { days or fewer. }\end{array}$ \\
\hline Tobacco & Percentage of high school students who currently smoke. \\
\hline Alcohol & $\begin{array}{l}\text { Percentage of high school students who say that within the last } 30 \text { days } \\
\text { drank alcohol at least once. }\end{array}$ \\
\hline Physical Activity & $\begin{array}{l}\text { Percentage of high school students who say that on an average school } \\
\text { day, they watch TV at least } 2 \text { hours or more. }\end{array}$ \\
\hline
\end{tabular}

Source: 2009 Youth Risk Behavior Survey, 2008-2009 Information Works! 
